\title{
Highly Effective Security Techniques in OSN Based on Genetic Programming Approach
}

\author{
Y. N. S. R. Bharadwaj, K. Raja Sekhar \\ Department of Computer Science and Engineering, K L University, India
}

\begin{tabular}{l} 
Article Info \\
\hline Article history: \\
Received Jun 7, 2017 \\
Revised Aug 18, 2017 \\
Accepted Aug 24, 2017 \\
\hline
\end{tabular}

\section{Keyword:}

Genetic algorithm (GA)

Information security

Online social networks

Privacy enhancing technology

Risk reduction

\begin{abstract}
Assurance is one of the grinding centers that enhances when trades get mediated in Online Community Techniques (Online Social Networks). Diverse gatherings of utilization innovation specialists have limited the 'OSN security issue' as one of surveillance, institutional or open security. In taking care of these issues they have moreover overseen them just as they were person. We adapt that the elite security issues are caught and that evaluation on genuine feelings of serenity in Online Social Networks would advantage from a more exhaustive method. Nowadays, points of interest systems mean a critical piece of relationship; by losing security, these organizations will decrease a ton of pleasant areas to see as well. The inside motivation behind subtle elements security (Information Security) is risk control. There are a great deal of discovering works and exercises in security danger control (ISRM, for example, NIST 800-30 and ISO/IEC 27005. Regardless, only few works of appraisal focus on Information Security danger diminishment, while the signs depict normal determinations and suggestions. They don't give any use ideas concerning ISRM; truth be told diminishing the Information Security dangers in questionable conditions is cautious. Subsequently, this papers joined an acquired counts (GA) for Information Security danger loss of weaknesses. Finally, the parity of the associated system was broke down through a reflection.
\end{abstract}

Copyright $\odot 2017$ Institute of Advanced Engineering and Science. All rights reserved.

\section{Corresponding Author:}

Y. N. S. R. Bharadwaj,

Department of Computer Science Engineering,

K L University,

Email: bharadwaj.y68@gmail.com

\section{INTRODUCTION}

Can clients have sensible wishes of security in Online Social Systems (Online Social Networks) Press audits, remotes and analysts have reacted to this question certifiably? Without a doubt in the "straightforward" globe made by the Face books, LinkedIn's and Twitter records of this globe, clients have bona fide security wishes that might be ignored. Associations are bit by bit in light of information structures (Iss) to enhance organization capacities, spur administration decision making, and express organization frameworks.

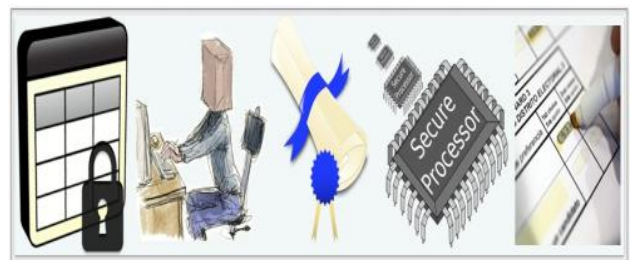


Figure 1. Social Network Process Generation with Secure Process

In the present our planet, dependence has drawn out and an assortment of exchanges, for example, the managing of items and organizations are constantly satisfied electronically. Expanding productive dependence on Iss has persuaded a breaking down expansion in the effect of points of interest security (Information Security) sick employments. In this article, we bargain that these elite security issues are taken, and that OSN customers might profit by a superior synchronization of the three methods. For instance, consider surveillance and group security issues. OSN suppliers have accessibility to all the client made substance and the capacity to pick who might have induction to which points of interest. This might quick group security issues, e.g., OSN suppliers might create content deceivability in overriding so as to astonish applications present security choices. Therefore, different the security issues customers' commitment with their "associates" may not be their very own result activities, yet rather come to fruition in view of the essential alternatives movements realized by the OSN organization. If we concentrate on the security issues that appear from confused options by clients, we may end up deemphasizing the way that there is a main factor with the ability to concentrate the attention and use of details.

Subsequently, Information Security is an essential issue that has sucked in much worry from both IS experts and experts. IS experts use controls and diverse countermeasures, (for instance, perceiving which IS possessions are not capable against perils) to evade security crushes and secure their advantages from distinctive danger outlines. Regardless of, such use does not for the most part totally ensure against dangers as a result of regular control downsides. Subsequently, opportunity assessment and diminishment are the essential moves to be made towards Info security hazard control (ISRM). Right now, most researchers are dealing with danger assessment yet frequently lack of concern the danger diminishing point of view. As an effect of danger assessment alone, IS hazard just gets analyzed however not diminished or diminished since danger diminishment is really troublesome and loaded with uncertainty. The issue of week nesses present in the danger diminishing system is one of the crucial segments that effect ISRM sufficiency. Thusly, it is critical to manage the week nesses issue in the Info security hazard diminishment strategy. To do in this way, we propose an Info security hazard diminish style centered around a Got Requirements (GA). According to the essential results, our suggested style can feasibly diminish the danger reasoned from unverifiable circumstances.

\section{BACKGROUND WORK}

The arrangement of enhancements that we suggest as "Security Enhancing Technologies" (SET) created out of cryptography and machine security assess, and are hence organized after security making particulars, for instance, hazard showing and security appraisal. Recognized security improvements were designed for national security reasons, and later, for acquiring company data and transactions. They were developed to secured state and company endowed concepts, and to secure requested features from disruptions.

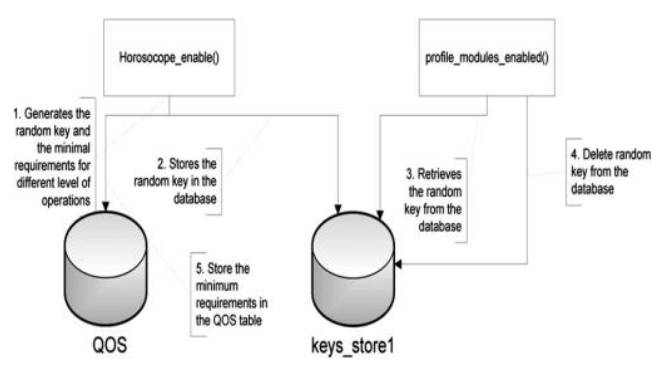

Figure 2. Random Key Generation for Authentication and Minimal Requirements Specification

The protection problems managed to by Creatures are from several views a reformulation of old protection threats, for example, convenience jolts or foreswearing of control strikes. This time on the other hand, conventional people are the structured clients of the improvements, and surveillant arrays are the harmful components from which they require protection. Obviously, the best client and use of Creatures is the "extremist" loaded with government distinction. The objective of Creatures in the connection of Online Social Networks is to motivate people to amuse with others, provide, get to and distribute details on the web, free from declaration and obstacle. Probably, just details that a client particularly imparts is available to her structured individuals, while the divulgence of another details to another activities is prevented. Moreover, 
Creatures plan to improve the capability of a client to distribute and accessibility details on Online Social Networks by offering her programs to prevent control. As for declaration, the review of Creatures begins from the preface that possibly ill-disposed components work or display Online Social Networks. These have an interest toward getting keep of however much client details as could be expected, such as client designed material (e.g., material, pictures, personal messages) and also cooperation and actions details (e.g., description of associates, websites analyzed, 'likes'). Once an ill-disposed aspect has acquired client details, it may apply it as a part of surprising ways - and even to the hindrance of the people connected with the facts.

In HCI analysis it is expected that particular results that assess protection with defending are so unbending it would be difficult support the clients' techniques. Information defending does not so much suggest protection, and visibility is not unavoidably connected with (undesirable) availability. Every day techniques, for example, making unequivocal that you would choose not to be concerned, review that a divulgence might be used to arrange protection limitations. Further, analysis demonstrate that clients make their own techniques to keep up their protection and cope with their character while enjoying taking an interest in Online Social Networks. Very good example, a few clients make various details at a given control. These may be pseudonymous, gloomy or obvious details. While these "clouded" details may not protect the clients' details effectively, clients find that the protections they provide are sufficient for their every day need.

\section{PROPOSED APPROACH}

Evaluating the relative risk for every powerlessness is professional by means of a strategy called risk evaluation. Threat evaluation allocates a risk position or position to every particular weakness's. Positioning rouses one to decide the relative danger associated with each not capable information ownership. The danger components fuse resources, dangers, powerless focuses and weaknesses. Property significantly consolidate the, regular message, innovation and structure of a system. Dangers are things that can happen or that can "strike" the structure. Shortcomings make a system more arranged to be struck by a danger or consider the shot of an assault to more planned have a couple achievement or impact. Shortcomings are an advantage's components that might be abused by a danger and join downsides. It is mistaken to know everything about every single feeble point. In this way, an alternate that data for uncertainty ought to reliably be added to the danger assessment system, which incorporates an assessment made by the trough using awesome judgment and experience. Really, dangers are addressed by breaking down the potential outcomes of dangers and feeble focuses and by considering the planned impact of a negative security appear and, for example, weaknesses.

\section{GENETIC PROGRAMMING APPROACH}

CGA counts are inquiry figuring's centered on the strategies for run of the mill duty and nonpartisan acquired capacities. They be a part of together accomplishments of fittest among arrangement components with a system yet randomized data organization to structure a wish counts with a part of the noteworthy outline of individual inquiry. In each period; another arrangement of made creatures (string) is produced utilizing elements of the fittest of the old; an occasional new viewpoint is made progress toward great survey. They effectively disregard affirmed data to consider on another wish centers with expected upgraded proficiency. Hereditary computations have been produced by Johan Holland and his partners at the University of Mich. The destinations of their finding have been twofold:

a. To draw in out and altogether portray the adaptable strategies for highlight system

b. To procedure recreated structures development that keeps the imperative data in both element and made systems mechanical innovation.the GA has a few varieties from more ordinary upgrade and search for methodology in: 1-Gas perform with a development of the parameter set, not parameter themselves. The Gas require the element parameter set of the enhancing issue to be distributed as a restricted length arrangement over some constrained letters set. 2-Gas look from a tenants of centers not anchorman. 3Gas use result (destination limit) data, not backups or other partner contemplating. 4-Gas use probabilistic movement controls not deterministic proposals .An acknowledged acquired counts is produced out of three executives: Replication, Cross-over, and Mutation.

\section{EXPERIMENTAL EVALUATION}

The danger identifiable confirmation process begins with an evaluation, in which stage an affiliation's points of interest should be masterminded and arranged moreover. At that element, the points of interest should be organized as demonstrated by their vitality. In every one level, subtle elements is gathered from organizations through talking about with specialists and distributed studies. For arranging and 
distinguishing assets, once the beginning stock is gathered, it must be settled whether the advantages sessions are effective to the affiliation's danger administration framework. Such a survey might make overseers further subdivide the sessions to make new classifications that better help the danger administration framework.

$$
\begin{aligned}
& \text { Risk Rate }=V A \times L V-(V A \times L V) \times \\
& M C+(V A \times L V) \times U V
\end{aligned}
$$

Where VA means the data resource esteem (1 to 100). LV demonstrates the probability of shortcomings occurrence (0 to 1$)$. Symbolizes the rate of risk lessened by present oversees (0\% to $100 \%)$ and alludes to the uncertainty of present information of shortcomings is $(0 \%$ to $100 \%)$. It is gathered that $\mathrm{VA}=$ $100, \mathrm{LV}=0.5, \mathrm{MC}=0.5$ and $\mathrm{UV}=0.2$. By utilizing $\mathrm{GA}$, we need to decline rate of risk to 0 . Components of risk evaluation are utilized as wellbeing and wellness work variables. The wellbeing and wellness work for GA is:

$$
\begin{aligned}
& Y=\text { Risk_Function }(X) \\
& Y=X(1) \times X(2)-(X(1) \times X(2)) \times \\
& X(3)+(X(1) \times X(2)) \times X(4)
\end{aligned}
$$

Connected with every individual is wellness esteem. This worth is a numerical evaluation of how great of answer for streamlining issue the individual will be.

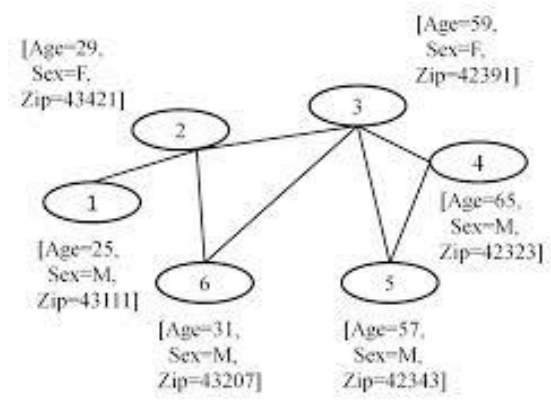

Figure 3. Architectural Representation of the Social Communication

Individual with inherited post discussing to better outcome has higher health and health and fitness features, while lower health and health and fitness features are acknowledged to those whose bit sequence talks to poor outcome. The health and health and fitness potential could be one of two sorts: development or minimization. Plus the health and health and fitness work, the majority of the specifications on option factors that in fact direct whether an answer is a realistic one ought to be revealed. All infeasible outcomes are discarded, and health and health and fitness capabilities are realized for the realistic ones. The outcomes are rank-requested focused around their health and health and fitness values; those with better health and health and fitness features are given more possibility in the infrequent option process.

\section{CONCLUSION}

Particular focused on following of informal community exercises concerning a specific customer is an amazing framework (PET) as for its capability to manage accommodation violators and forceful con artists and that its capacity to support obligation of an interpersonal organization customer's exercises. By taking a gander at different current innovation and sample situations where activity following has been utilized on a customer's record, we recognize that there are both regular scientific, specialized and lawful confinements to the potential for following to finish wide scale executions. The numerical and specialized angles are secured as forgot prerequisites systems obviously which require some amazing adjusting. In spite of the fact that guidelines harp the capability of following to bring about genuine damage to an individual, it really areas genuine restrictions on how this technique can be utilized as a part of a free and majority rule bunch regarding different people. 


\section{REFERENCES}

[1] Boase, J., \& Wellman, B. (2006). "Personal Relationships: On and Off the Internet",

[2] McLuhan, M. (1964), "Understanding Media: The Extensions of Man. Cambridge: MIT Press. O'Reilly" (O'Reilly, 2005)

[3] Adamic, L. A., \& Adar, E. (2003). Friends and Neighbors on the Web. Social Networks.

[3] Ronald," Privacy-Enhancing Technologies White Paper for Decision-Makers", Koorn RE (editor), Drs. Herman van Gils RE RA Drs. Joris ter Hart, Dr. Ir. Paul Overbeek, Drs. Raúl Tellegen

[4] Anne Alexander "The Egyptian Experience: Sense and Nonsense of the Internet Revolution, Details of the Internet shutdown and restoration can be found on the Renesys", blog, J. Cowie, (January 27, 2011; February 2, 2011).

[5] Mohamed Shehab A, Anna Squicciarini B, Gail-Joon Ahn C, and Irini Kokkinou "Access Control for Online Social Networks Third Party Applications", Available Online At www.Sciencedirect.Com Journal Homepage: www.Elsevier.Com/Locate/Cose Computers \& S E C U Rity 31 (2 $\begin{array}{lllllllll}2 & 0 & 1 & 9 & 7 & \text { E9 } & 1 & 1 & 0167-4048 / \$ \text { E See Front }\end{array}$ Matter $^{\text {a }} 2012$ Elsevier Ltd. All Rights Reserved. http://Dx.Doi.Org/10.1016/J.Cose.2012.07.008.

[6] Heather Richter Lipford, Katherine Froiland "Visual vs. Compact: A Comparison of Privacy Policy Interfaces", in CHI 2010: Input, Security, and Privacy Policies April 10-15, 2010, Atlanta, GA, USA.

[7] Ming-Chang Lee "Information Security Risk Analysis Methods and Research Trends: AHP and Fuzzy Comprehensive". International Journal of Computer Science \& Information Technology (IJCSIT) Vol 6, No1, February 2014.

[8] Nan Feng, Xue Yu “A Data-driven Assessment Model for Information Systems Security Risk Management", in Journal of Computers, Vol. 7, No. 12, December 2012.

[9] http://policyreview.info/articles/analysis/necessary-and-inherent-limits-internet-surveillance.

[10] Seda G"urses and Claudia Diaz "Two tales of privacy in online social networks", This article appears in the IEEE Security \& Privacy 11(3):29-37, May/June 2013. This is the authors' version of the paper. The magazine version is available at: http://www.computer.org/csdl/mags/sp/2013/03/msp2013030029-abs.html.

[11] F. Beato, M. Kohlweiss, and K. Wouters "Scramble! Your social network data." Privacy Enhancing Technologies Symposium, PETS 2011, volume 6794 of LNCS, pages 211-225. Springer, 2011.

[12] E. De Cristofaro, C. Soriente, G. Tsudik, and A. Williams "Hummingbird: Privacy at the time of twitter." IEEE Symposium on Security and Privacy, pages 285-299. IEEE Computer Society, 2012.

[14] Rula Sayaf and Dave Clarke "Access control models for online social networks." Social Network Engineering for Secure Web Data and Services. IGI - Global, (in print) 2012.

[15] Fred Stutzman and Woodrow Hartzog "Boundary regulation in social media.” by, In CSCW, 2012.

[16] Alireza Tamjidyamcholo and Rawaa Dawoud Al-Dabbagh "Genetic Algorithm Approach for Risk Reduction of Information Security", International Journal of Cyber-Security and Digital Forensics (IJCSDF) 1(1): $59-66$ the Society of Digital Information and Wireless Communications, 2012 (ISSN: 2305-0012). 